\title{
Secondary Students' Views about Creativity in the Work of Engineers and Artists: A Latent Class Analysis
}

\author{
Danielle B. Harlow, Karen Nylund-Gibson, Ashley Iveland, Lauren Taylor \\ Department of Education, Gevirtz Graduate School of Education, University of California Santa Barbara, \\ Santa Barbara, USA \\ Email: dharlow@education.ucsb.edu
}

Received March $6^{\text {th }}, 2013$; revised April 10 ${ }^{\text {th }}, 2013$; accepted April 22 ${ }^{\text {nd }}, 2013$

Copyright (C 2013 Danielle B. Harlow et al. This is an open access article distributed under the Creative Commons Attribution License, which permits unrestricted use, distribution, and reproduction in any medium, provided the original work is properly cited.

\begin{abstract}
To close the current "innovation gap”, schools must help students develop creative thinking skills and understanding of technical careers as requiring creativity. A first step is understanding students' current perceptions of the work of such careers. The goal of this study was to identify patterns in how secondary school students viewed the work of a technical career, engineering, in comparison to art, a career more traditionally associated with creativity. The sample consisted of 104 students (ages 13 - 15) entering their first year of a program that intentionally integrates engineering, science, and art instruction. The students in our study completed two assessments during their first week of school. On one side of a paper they drew an engineer and answered questions about what engineers do. On the other side of the paper, they drew an artist and answered questions about what artists do. These drawings and associated writing were coded. We then used the statistical method of latent class analysis to model the responses. We identified three patterns in the ways that students perceived the work of engineers and two patterns in the ways that students perceived the work of artists.
\end{abstract}

Keywords: Engineering; Art; Latent Class Analysis; Secondary Education

\section{Introduction}

In the United States, engineering has been largely absent from pre-college education. This means that only those students who choose to pursue engineering at the undergraduate level have the opportunity to develop sophisticated understandings of engineering. Fortunately, this is changing. The recently drafted, A Framework for K-12 Science Education: Practices, Crosscutting Concepts and Core Ideas (NRC, 2012), considers science and engineering practices as integral to science instruction. This means that soon science teachers will be teaching engineering practices and habits of mind to even our youngest students.

Integrating engineering into $K$-12 programs has many potential benefits: "improved learning and achievement in science and mathematics; increased awareness of engineering and the work of engineers; understanding of and the ability to engage in engineering design; interest in pursuing engineering as a career; and increased technological literacy" (Katehi, Pearson, \& Feder, 2009: pp. 49-50). Learning engineering will not only benefit those who eventually pursue engineering or technology careers, it will benefit all students. Indeed, engineering "habits of mind" include systems thinking, creativity, optimism, collaboration, communication, and attention to ethical considerations, the very qualities considered imperative for working in the $21^{\text {st }}$ century (e.g., Trilling \& Fadel, 2009).

Recently, business leaders have identified an "innovation gap" between the qualities desired for employees and the actual qualifications of applicants (e.g., Casner-Lotto \& Barrington,
2004). The workforce is not prepared to do innovative work and meet the demands of the new business and technologydriven world. One contributing factor to this innovation gap may be that instruction emphasizing creativity is lacking in most engineering programs, both at the $K-12$ and post-secondary levels.

Innovation is related to creativity through the process of engineering design, the process of developing a new product or solution to a problem that meets the goals of a client while working within constraints. Researchers of engineering agree on the stages of the design process, with slight variations in the naming of the stages and acknowledgement that, in practice, engineers may not pass through the stages in a linear fashion. These stages include establishing a need, analyzing the task, conceptual design, embodiment design, detail design, and implementation (Howard, Culley, \& Dekoninck, 2008). Carefully moving through this process results in a solution that is appropriate for the task, but does not necessarily result in a solution that is novel or innovative. To be innovative, one must engage in the creative process of generating, evaluating and analyzing ideas in one or more stages of the engineering design process (Howard, Culley, \& Dekoninck, 2008). In fact, the National Academy of Engineering states that "creativity (invention, innovation, thinking outside the box, art) is an indispensable quality for engineering, and given the growing scope of the challenges ahead and the complexity and diversity of the technologies of the 21st century, creativity will grow in importance" (NAE, 2004: p. 55). This is in sharp contrast to a widespread public belief that creativity is not part of engineering 
(Kazerounian \& Foley, 2007; Schmidt, 2011).

In efforts to help students develop creative skills in concurrence with more technical skills, some educators are calling to integrate arts education into the more technical disciplines of science, technology, engineering, and mathematics (STEM). This movement has been termed STEAM education which stands for science, technology, engineering, art, and mathematics. STEAM has been described as "science and technology, interpreted through engineering and the arts, all based in a language of mathematics" (Yakman, 2008). STEAM education, which advocates for integrating STEM with an all-inclusive definition of the arts, has been gathering momentum internationally. Two recent studies in Korea used a STEAM model to integrate the sciences and arts at the elementary and early high school levels (Yakman, 2010; Kwon, Nam, \& Lee, 2011). Related movements initiated by art advocates include STEM-A (http://stem-a.org/) and stem-arts (http://www.stemarts.com/). Finally, the art of science learning

(http://www.artof-sciencelearning.org/), funded by the National Science Foundation, explores how arts-based learning can improve science learning at all ages.

The work of engineers involves designing a product that meets a client's needs and includes aesthetic considerations along with financial, safety, and other constraints. In programs that integrate STEM content with art, students engage in the practices associated with engineering as well as art. Depending on the curricular design, these may be simultaneous experiences or separated in time. One would expect that participating in the work of both engineering and art would help students develop more sophisticated understandings about the work of these professionals.

Since the early 1980's, researchers have investigated students' ideas about the work of professionals by asking students to draw. The initial Draw a Scientist Test (Chambers, 1983) elicited several consistent characteristics that appeared in young children's drawings of scientists. Later iterations of this assessment tool looked at the impact of media, gender, and older students' perceptions (for a review of this literature see Finson, 2002). The Draw a Scientist Test (DAST) has since been adopted for a variety of professions. Knight and Cunningham (2004) adopted the DAST for use with Engineering. In their version, students responded to the following five questions, "In your own words what is engineering?" "What does an engineer do?" "Draw a picture of an engineer at work" "Do you know any engineers?” "If yes, then who are they?” (p. 2529). They administered the Draw an Engineer Test (DAET) to 384 students in grades 3 - 12 and found that the most common activities associated with engineering were building (30\%) and fixing (28\%) followed by creating (17\%) and designing (12\%). Later, Capobianco, et al. (2011) administered the Draw an Engineer Test (DAET) to 400 elementary school children. The children in this study depicted engineers as mechanics, laborers, technicians, and designers.

We used a modified version of this assessment to understand students' ideas about the work of both engineers and artists. We hypothesized that students would consider artists to be creative and engineers to be logical. We tested this hypothesis by having freshmen in a high school engineering academy draw engineers and artists and answer questions about the work of engineers and artists. We then coded these data and modeled the data using the statistical procedure of latent class analysis (LCA) to better understand the patterns in the data.
Our study was guided by three research questions: 1) Are there patterns in how secondary students entering an engineering academy think about the work of engineers? 2) Are there patterns in how secondary students entering an engineering academy think about the work of artists? 3) How are these patterns related to each other?

\section{Study Design}

This study included a qualitative stage and a quantitative stage. We collected qualitative data consisting of student drawings in response to specific prompts (described below). We then coded these data through an emergent coding process. The codes were then analyzed using latent class analysis. Below we describe the research context, the methods of data collection and the qualitative and quantitative data analysis process.

\section{Research Context}

This study took place at an Engineering Academy within a public high school in California, USA. In the year prior to this study, the school served approximately 2300 students of which 48\% were Caucasian, 37\% Hispanic, 9\% Asian, and 2\% were African American. Nearly a quarter (23\%) of the students were disadvantaged socioeconomically. The school housed a nationally recognized competitive engineering academy that admitted approximately 100 freshmen each year. The Engineering Academy enrollment in 2012-2013 was 104 students roughly evenly divided by gender ( $53 \%$ female). The population was nearly three quarters (74\%) White, 19.6\% Asian, 1.8\% African American, 1.8\% Filipino and 1.8\% American Indian. Sixteen percent of the students reported that they were of Hispanic or Latino ethnicity. These 104 freshmen made up our study population.

In the Engineering Academy, physics, computer programming, engineering, and art are intentionally integrated. Students in this program spend one hour a day in the engineering academy doing course work dedicated to engineering, physics, art, and computer science. The rest of their course work is completed in the regular high school. Curriculum is developed around projects that require students to integrate knowledge from all of these areas. For example, one project that students complete is a light sculpture. The students design the sculpture using computer aided design (CAD), use lathes and other equipment to machine parts of the sculpture, and program the lights to go on and off in an aesthetically pleasing way. This requires knowledge of machining, circuits, art, and computer programming. These smaller projects lead into a capstone project in which the seniors form a robotics team and compete in a national robotics competition.

\section{Data Collection: Draw an Engineer and Draw an Artist}

During their first week of school, entering freshmen completed a modified Draw an Engineer Test. On one side of a piece of paper, each student answered the questions, "In your own words, what is engineering?" and "What does an engineer do?” They also drew a picture of an engineer at work, and wrote a brief description of what was going on in the drawing. On the other side of the paper, the students answered similar questions related to art, "In your own words, what is art?" "What does an artist do?" They drew a picture of an artist at 
work, and wrote a brief description of what was going on in their drawing. Two responses to the engineering task and two responses to the artist task were too light to be legible and could not be used in the analysis. Thus our resulting data set consisted of 102 responses to both the "Draw an Engineer Test" and to the "Draw an Artist Test."

\section{Qualitative Analysis: Coding Drawings}

The engineering drawings were coded with binary codes (lack of presence/presence). The initial coding scheme was based on that developed by Capobianco, and others (2011). It was modified during initial coding as additional codes emerged and codes were combined and collapsed. Since our population was older than the population in Capobianco et al. (2011) and, further, were entering a selective engineering academy we expected that our population would have more sophisticated understandings of the work of engineering. We had no initial model for coding the artist task and thus, those codes were emergent.

Our aim was to construct a coding scheme that could be used for both the engineering and artist portion of the activity. Our resulting coding scheme consisted of the following types of codes: Actions (what was done by engineers/artists), the output (object), qualities of the output, purposes of the work, requirements (inputs) for the work, and details about who did the work. Our initial scheme also coded particular types of clothing (e.g., lab coats on the engineers, berets on the artist) and tools (e.g., paintbrushes and screwdrivers) but these two categories of codes were not included in the statistical analysis. Finally, we coded the gender of the drawn engineer and or artist. This was determined primarily by pronouns used in the students' descriptions of the picture (e.g., "The engineer is inspecting her work," "He is working on a robot"). Although many drawings looked like they were intended to depict males or females (e.g., short hair, jeans for men, hair bows and skirts for females), unless a gender-specific pronoun was used, they were assumed to be non-specific to gender. As a result, we likely under-coded the number of "male" drawings for both artists and engineers.

Our coding process included coding a subset of the data by two independent coders. Coding was then compared and discussed. This led to a refinement of the coding scheme including collapsing codes into larger categories. This process of coding, comparing, and refining was continued until an interrater reliability over $80 \%$ was attained. All data were then recoded with the new coding scheme. Differences in codes during the final round were discussed until consensus.

\section{Quantitative Analysis: Latent Class Analysis}

The second stage of the analysis involved using the statistical method of LCA (Dayton, 1998; Magidson \& Vermunt, 2004) as a way of exploring whether there were patterns in students' drawings. LCA is an exploratory multivariate analysis, similar to cluster analysis, that can use the codes from students' drawings to identify latent classes of students. These classes are based on binary codes meaning that the code was either present or not (see Harlow, Swanson, Nylund-Gibson, \& Truxler, 2011 for another example of using LCA to interpret students' drawings of science ideas). Different than the more commonly used factor analysis, LCA groups individuals whereas factor analysis groups items (or codes). In LCA, there are no assumptions made about which codes would group together or how many groups (or classes) students would be sorted into. LCA uses the term "class" to refer to the grouping of individuals, but for this paper we will use the term "group" to avoid confusion with the term classes to refer to classrooms or age level groupings of students. LCA models are fit in a series of steps. First, a oneclass model is fit and then the numbers of groups (classes) is increased. Each new model (with an increase in the number of groups) is compared to the previous model. The model with the greater number of groups is selected only if increasing the number of groups results in conceptually meaningful groupings and provides a good statistical fit. This was done for engineering and art independently. In addition, fit indices were used to help determine the ideal number of conceptually meaningful groups (Nylund, Asparouhov, \& Muthén 2007). The models were run with Mplus version 7.0 (Muthèn \& Muthèn, 19982012).

We used a subset of the codes described above in the LCA models. Specifically, we selected those codes that showed differences among groups identified by LCA within each profession. This means that if a particular code was identified in nearly all or very few responses, it was not included because that code would not differentiate the groups. For example, the code "communicate" was only found on one engineering response so it was unlikely to show how the groups differed and was not included for the engineering response. However, it was found on 60 of the art responses and therefore was likely to distinguish the groups and was included for the LCA analysis of the artist responses.

The following codes were used for the latent class analysis. Some codes were used for both the engineering and art LCA (indicated with E/A). Others were used only for the engineering (E) or the art (A) LCA.

Gender:

1) Draw Male (E/A). Drawing was of a male and student used male pronouns (he, him, his) when writing about what the engineer or artist was doing.

2) Draw Female (E/A). Drawing was of a female and student used female pronouns (she, her) when writing about what the engineer or artist was doing.

What an artist or engineer does:

3) Create $(E / A)$. The engineer or artist was thinking creatively or being creative.

4) Imagine $(E / A)$. The engineer or artist imagined or visualized an idea.

5) Design (E/A). The engineer or artist designed something.

6) Make (E/A). The engineer or artist made something.

7) Skills $(E)$. Verbs indicating a particular skill that could be learned. Examples from engineering include computer programming, drawing, and drafting. Examples from art include draw, paint, and sing.

8) Do/Work (E). Vague statements such as, "He does work" or "She does art".

9) Logic (E). Going through a particular set of steps or solving a problem that has an assumed right answer. Words include discover, solve, test, think.

$10)$ Tinkering $(E)$. The artist or engineer was manipulating an existing object to improve it in some way

11) Maintain (E). The artist or engineer was manipulating an existing object to repair or maintain.

12) Communicate (A). Art or engineering included communicating or expressing ideas.

Output/Product of work: 
13) For others $(E / A)$. The end product of the work of the engineer or artist was for others. Included statements like, "for others' enjoyment” and “to help others”.

Requirements for work/Inputs:

14) Thought (E). Students indicated that thought was required or that the engineer or artist used his or her own thoughts.

$15)$ Ideas $(E)$. Students indicated that ideas were required.

16) Knowledge $(E)$. Students indicated that knowledge was required. While this is similar to both thought and ideas, we considered it separate because knowledge implies an existing body of knowledge.

17) Emotion $(A)$. Students indicated that emotions were required.

\section{Findings}

\section{Qualitative Results}

The number of responses coded with each code is listed in Table 1. The first three codes (create, design, and imagine) are codes we associated with traditional definitions of creativity. A little over half of the students (53 students) explicitly associated creativity (or the action of creating something) with engineering. 40 students stated that designing was part of engineers' work and 20 students claimed that imagining was part of engineers' work. This is compared to 62 students stating that artists create things or use creativity, 32 stating that artists imagine and only 7 reporting that artists design. Both codes of create and imagine were more similar across the two disciplines than we anticipated.

Codes that were found much more often among the engineering responses as compared to the artist responses include work, construct, tinker, maintain, logic, knowledge, for others. In contrast, codes that were more common among responses

Table 1.

Number of responses including each code.

\begin{tabular}{ccc}
\hline Code & Engineering & Art \\
\hline Create & 53 & 62 \\
Design & 40 & 7 \\
Imagine & 20 & 32 \\
Make & 26 & 17 \\
Do/work & 17 & 6 \\
Construct & 71 & 4 \\
Tinker & 12 & 2 \\
Maintain & 22 & 0 \\
Logic & 33 & 5 \\
Skills & 40 & 89 \\
Knowledge & 37 & 1 \\
Thought & 15 & 25 \\
Ideas & 16 & 25 \\
Communicate & 0 & 60 \\
Emotion & 0 & 41 \\
For others & 41 & 19 \\
Drew Male & 41 & 27 \\
Drew Female & 10 & 16 \\
\hline
\end{tabular}

about artists include skills, thought, ideas, communication and emotion. Further, more of the responses about artists included females while the responses about engineering included more males.

The qualitative analysis alone provides interesting insight to how freshmen students in an engineering academy perceive the work of engineers and artists. Over half the students see each career as involving creativity. The students do indicate major differences between the two careers. Engineering is perceived to be more logical and requiring knowledge. In contrast, artists are depicted as more emotional and requiring skills such as the ability to paint, draw, or play instruments. A few of the students noted connections between the work of artists and engineers. For example, one student (student 64) wrote on the draw an engineer test, "Really: an engineer is an artist" and conversely, on the draw an artist test, wrote, "Really: an artist is an engineer." Other students made explicit connections between the disciplines by calling engineering "an art." What the qualitative data does not allow us to immediately perceive is the patterns within the ways of thinking about each career. For that we turn to the statistical method of modeling the data using Latent Class Analysis.

\section{Deciding the Number of Groups}

Table 2 presents the model fit information for the LCA models estimated for both art and engineering. The indices used for the analysis are the commonly accepted ones used in LCA applications. With both the Bayesian information criteria (BIC) and the Adjusted BIC (ABIC), the model with the lowest value indicates the better fitting model. Also, two other fit statistics used were the Lo-Mendell-Rubin likelihood ratio test (LMR LRT, referred to as LMR) and the bootstrap likelihood ratio test (BLRT). These provided a $p$-value that was used to compare neighboring group models (i.e., 2-group vs. a 3-group). For further information on LCA and the methods used to determine the appropriate number of group (classes), see Nylund et al. (2007).

Table 2 presents fit information for both the engineering and art LCA models considered. For the engineering drawings, we fit 1 through 4 groups, and for the art we fit 1 through 3 groups. When examining the results of the engineering drawings, both the AIC (1645.65) and ABIC (1620.11) show significant decreases in the decreasing pattern when comparing 3 groups to 4 , suggesting that the addition of the $4^{\text {th }}$ group does not provide a significant increase in fit to the 3 group. This is further supported by the BLRT, which shows a non-significant $p$-value for the 4-group solution, indicating that the 3-group model is preferred. The BIC shows an irregular pattern from those seen in most applications, where it increases in values after the adding more groups. The entropy for the engineering LCA is high at .88, indicating good classification into the group. In sum the majority of fit statistic for the engineering LCA point to a 3-group solution.

The model fit for the LCA of the art drawings consistently pointed toward a 2-group model based on the AIC (980.76), BIC (1030.82), and ABIC (970.80). This solution is further justified by the LRM and BLRT that both show a non-significant $p$-value for the 3-group solution, indicating that the 2groupsolution is the best fit for the art drawings. The entropy for the art LCA is also reasonably high at .80. In sum, these results indicate that a 2-class solution fits best for the art drawings. 
Table 2.

Fit indices for the engineering and art drawings model solutions.

\begin{tabular}{|c|c|c|c|c|c|c|c|}
\hline Class & Log Likelihood & AIC & BIC & ABIC & LMR/p-value & BLRT/p-value & Entropy \\
\hline \multicolumn{8}{|c|}{ Engineering } \\
\hline 1 & 1883.01 & 1699.35 & 1738.58 & 1691.20 & $\mathrm{n} / \mathrm{a}$ & $\mathrm{n} / \mathrm{a}$ & $\mathrm{n} / \mathrm{a}$ \\
\hline 2 & 1611.21 & 1669.40 & 1750.47 & 1652.56 & 61.13/.14 & $-834.68 / .01$ & 0.82 \\
\hline 3 & 1699.30 & 1645.65 & 1768.56 & 1620.11 & $55.01 / .11$ & $-803.70 / .01$ & 0.88 \\
\hline 4 & 1727.98 & 1644.62 & 1809.37 & 1610.39 & 32.59/.35 & $-775.83 / .18$ & 0.88 \\
\hline \multicolumn{8}{|l|}{ Art } \\
\hline 1 & 280.35 & 1006.68 & 1030.39 & 1001.97 & $\mathrm{n} / \mathrm{a}$ & $\mathrm{n} / \mathrm{a}$ & $\mathrm{n} / \mathrm{a}$ \\
\hline 2 & 290.59 & 980.76 & 1030.82 & 970.80 & $44.95 / .01$ & $-494.34 / .01$ & 0.80 \\
\hline 3 & 223.98 & 988.91 & 1065.31 & 973.71 & 11.61/.14 & $-471.38 / 1.00$ & 0.87 \\
\hline
\end{tabular}

\section{LCA Model Results for Engineering}

We use three groups to model the students' responses to the draw an engineer test. A clear difference can be seen between Engineering Group 1 (57.6\% of students) and Engineering Group 3 (11.8\% of students). Students sorted into Engineering Group 1 (represented by black line in Figure 1) depict engineers as professionals who have gained knowledge and skills and use logical thinking to do their work. Of the three groups, students sorted into Engineering Group 1 also have the lowest probability (32\%) of indicating that an engineer is creative.

In contrast, students sorted into Engineering Group 3 (dashed line on Figure 1) depict engineers as creative (100\%) and imaginative (100\%) individuals who use their own thoughts and ideas to do engineering work. This group was also the most likely to draw a female engineer. Engineering Group 2 (30.6\% of students, grey line on Figure 1) was more likely than students sorted into the other two groups to indicate that engineers maintained things and were the most likely of all the groups to portray a male engineer.

Once an LCA is fit, we can explore which of the latent groups each student belongs to. The model provides a probability of being in that group, called a posterior class probability, which allows us to feel confident in the assignment. In our application, each model had high entropy, implying that students are assigned with high precision, giving us confidence in using these posterior probabilities to assign students to groups. Based on their group assignment, we selected one sample student for each of the three groups to show their drawings (see Figure 2).

Student 77 was selected to represent Group 1. This student had a high probability, 91\%, of belonging to Engineering Group 1, and lower probability, 9\%, of being sorted into Engineering Group 2. This student wrote that an engineer is "a person who builds designs and maintains buildings, transportation and motors." Also, "Engineers help keep thing running and working. They also build all sorts of stuff." The drawing depicted a male engineer (as indicated by the description of the picture) "welding something” and "designing something."

Student 21 was sorted into Engineering Group 2 with 100\% probability and represents the group well. This student wrote that engineering is "building and designing tools and stuff" and drew an engineer "programming and figuring out how to build an infrared radar." As indicated by the description in the drawing area, the engineer is male.

Finally, for Engineering Group 3, we show the response of student 43 who had a $99 \%$ probability of being sorted into Engineering Group 3. This student wrote, "I think engineering

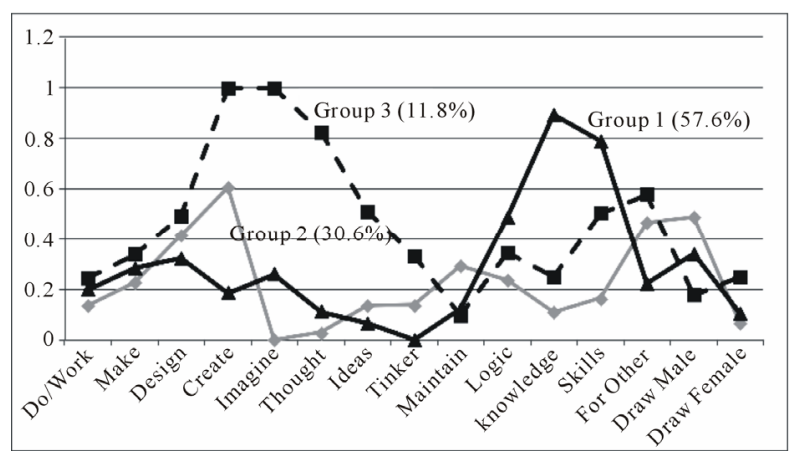

Figure 1.

Three-class LCA model for engineering.

is creating something/solving problems in an unique way. In other words, doing something using creative thinking and thinking outside the box.” This student also wrote, "An engineer does something that can help/inspire others and does something unique and special.” The drawing depicts plans for a children's hospital on the desk of an engineer. We can conclude that it is a female engineer's desk, although no individual is pictured, through the description of her image, "she is drawing”.

\section{LCA Model for Art}

Students were sorted into two groups according to their responses to the draw an artist test. A little over half (53.2\%) of students were sorted into Artist Group 1 (black line on Figure 3). This line peaks at the code communicate (100\% probability) which also included phrases such as "express themselves." Students sorted into Artist Group 1 were also highly likely to indicate that emotion (57\%) was important. In contrast, students sorted into Artist Group 2 (46.8\% of students) had a low probability of indicating the importance of communication and emotion and instead were most likely to mention creating something (74\%).

\section{Combining Engineering and Art}

Since we had each student's response for both the artist and the engineering exercise, we were able to cross their group membership for art and engineering, allowing us to see which patterns tended to go together. Looking at Table 3, we see that the 59 students who were in Engineering Group 1 (the groupfocused on logic and knowledge) were roughly evenly divided between the two classes of art responses. A little over 

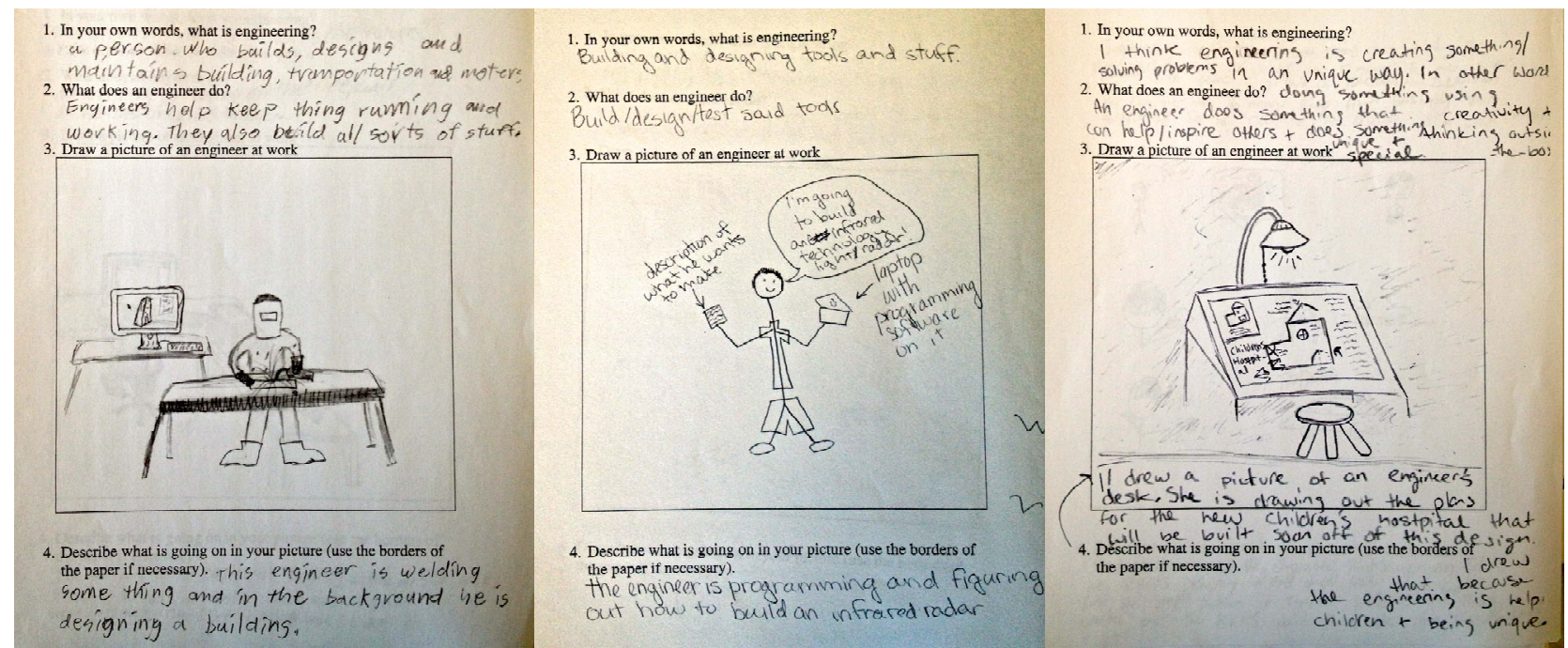

Figure 2.

Representative students for each of the three identified groups. Student 77 (left), Student 21 (middle), Student 43 (right) represent Groups 1, 2, and 3 respectively.

half of the students (52.5\%) were sorted into Art Group 1, the group focused on imagination and communication, while slightly less than half (47.5\%) were sorted into Art Group 2, which focused on the product of art. A similar trend can be seen for Engineer- ing Group 3 (the group most likely to indicate the importance of creativity and imagination in engineering. The trend for En- gineering Group 2, however, is different. Nearly two thirds of this group (65.5\%) were sorted into Art Group 1.

\section{Discussion}

Students appeared to have three distinct views of the work of engineers. The largest group of students (Engineering Group 1) viewed engineering as largely analytical, highlighting that en-

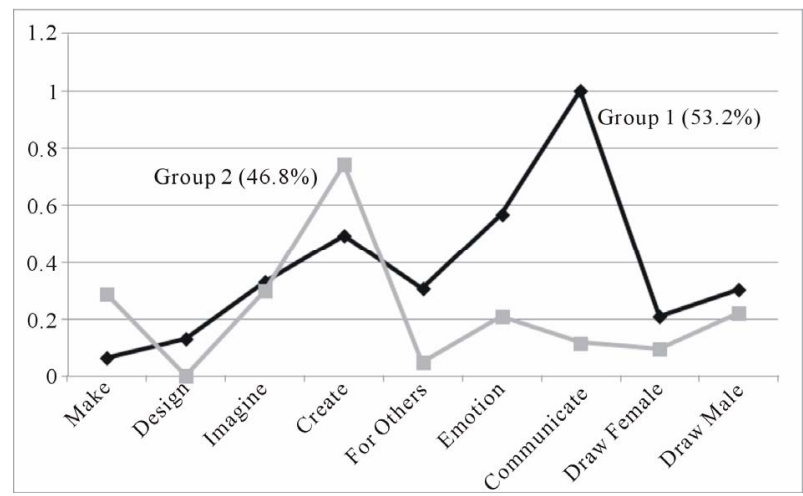

Figure 3.

Two-class LCA model for art.

Table 3.

Cross tabulation of engineering and art groups.

\begin{tabular}{ccc}
\hline & Group Art-1 & Group Art-2 \\
\hline Group Engineering-1 & 31 & 28 \\
Group Engineering-2 & 19 & 10 \\
Group Engineering-3 & 7 & 5 \\
\hline
\end{tabular}

gineering required knowledge and logical thinking. In contrast, the smallest group of students (Engineering Group 3) viewed engineering as a creative discipline. These students highlighted creativity, imagination, thoughts, and ideas while downplaying knowledge and logic. The other students (Engineering Group 2) were the most likely of the three groups to consider engineers as people who maintain things. These three groups of students represent the heterogeneity identified within the entire population of students. Note that that all three groups that emerged in our study population appear to hold relatively sophisticated, though incomplete, conceptions of the engineering profession. Unlike earlier studies, we did not find groups of students that held common misconceptions such as engineers as people who drive trains or engineers as only technicians. This is not surprising because our sample consisted of students entering a competitive engineering academy. Likely, students who held significant misconceptions about the engineering profession would not have applied to this program.

The students were sorted into two different views of artists. One group (Group 1) appeared to focus on the internal, less tangible aspects of art-emotion and expressing oneself. In contrast the other group (Group 2) which focused on the physical product.

In contrasting students' understanding of engineering work with that of the work of artists, we were able to investigate whether they saw engineering as significantly less creative. In fact, we did not see a large difference. While students did use the terms create and creativity slightly more often when describing artists, they used terms like design significantly more often when describing the work of engineering, indicating that there was not the large difference in this area that we expected. Instead, we found that the different groups of students were more or less likely to depict engineering as a creative discipline, with Engineering Group 3, representing only $11 \%$ of the students, highly likely to understand engineering as creative and Group 1, representing $57 \%$ of the students likely to see engineering as logical. Ideally, students would see engineering as requiring both creativity and logical and analytical thinking.

In the final step of comparing how each group of engineering 
students were sorted into groups based on their art response, we found that for two of the engineering groups (Groups 1 and 3), the students were roughly evenly sorted into the two art groups. Engineering Group 2, however, followed a different trend. Nearly two thirds of these students (65.5\%) were sorted into Art Group 1. This is a surprising result because this group of students was the most likely to depict engineering as maintaining something. They were not particularly likely to describe engineering as a creative or imaginative activity. This seems to be in opposition to their view of artists. It may be that students sorted into Engineering Group 2 were most likely to depict stereotypical images of both careers.

Our study was limited in a number of ways. We had a small sample size. Only 104 students were included in our study. A larger sample size could result in a larger number of groups and, thus, greater understanding of the differences among groups of students about their perceptions of the work of engineers and artists. Additionally, we did not include a comparison group. Our study consisted only of students from one secondary school and, further, only those who had self-selected, applied, and been admitted to an engineering academy.

Further research should include comparison groups of students who are entering a more typical secondary school program and a larger sample of students. In our own further research, we intend to conduct a longitudinal study of this population of students. As students progress in their education, we will conduct the draw an engineer test and the draw an artist test at repeated points in their education. This will allow us to understand how the patterns in their thinking change as they participate in a specialized engineering academy that intentionally integrates engineering and art.

It is vital that as we strive to help the next generation of students develop skills to be competitive in innovative careers like engineering, that they develop sophisticated and comprehensive understandings of the complexity of these careers. This is not only an issue of training those students who choose to pursue engineering careers, but a consideration that may impact recruitment of new students to pursue engineering careers.

\section{REFERENCES}

Barman, C. R. (1999). Students' views about scientists and school science: Engaging K-8 teachers in a national study. Journal of Science Teacher Education, 10, 43-54. doi:10.1023/A:1009424713416

Casner-Lotto, J., \& Barrington, L. (2006). Are they really ready to work? Employers' perspectives on the basic knowledge and applied skills of new entrants to the 21st century workforce. New York: The Conference Board.

Chambers, D. W. (1983). Stereotypic images of the scientist: The drawa-scientist Test. Science Education, 67, 255-265. doi:10.1002/sce.3730670213

Capobianco, B., Diefes-Dux, H. A., Mena, I., \& Weller, J. (2011). What is an engineer? Implications of elementary school student conceptions for engineering education. Journal of Engineering Education, 100, 304-328. doi:10.1002/j.2168-9830.2011.tb00015.x

Dayton, C. M. (1998). Latent class scaling analysis. Thousand Oakes, CA: Sage Publications

Ehrlén, K. (2009). Drawings as representations of children's conceptions. International Journal of Science Education, 31, 41-57. doi:10.1080/09500690701630455

Finson, K. (2002). Drawing a scientist: What we do and do not know after fifty years of drawings. School Science and Mathematics, 102, 335-345.

Harlow, D., Swanson, L., Nylund-Gibson, K., \& Truxler, A., (2011). Using LCA to understand students' responses to the question, "What is a Day?” Science Education, 95, 477-496.

Howard, T. J., Culley, S. J., \& Dekoninck, E. (2008). Describing the creative design process by the integration of engineering design and congnitive psychology literature. Design Studies, 29, 160-180. doi:10.1016/j.destud.2008.01.001

Kwon, S., Nam, D., \& Lee, T. (2011). The effects of convergence education based STEAM on elementary school students' creative personality. In T. Hirashima et al. (Eds.), Proceedings of the 19th International Conference on Computers in Education, Chiang Mai: AsiaPacific Society for Computers in Education.

Knight, M., \& Cunningham, C. (2004). Draw an engineer test (DAET): Development of a tool to investigate students' ideas about engineers and engineering. ASEE Annual Conference and Exposition, Salt Lake City, 20-23 June 2004

Katehi, L., Pearson, G., \& Feder, M. (2009). Engineering in K-12 education: Understanding the status and improving the prospects. Washington DC: National Academy Press.

Kazerounian, K., \& Foley, S. (2007). Barriers to creativity in engineering education: A study of instructors and students perceptions. Journal of Mechanical Design, 129, 761. doi:10.1115/1.2739569

Magidson, J., \& Vermunt, J. K. (2004). Latent class models. In D. Kaplan (Ed.), Handbook of quantitative methodology for the social sciences. Newbury Park, CA: Sage Publications. doi:10.4135/9781412986311.n10

Muthen, L. K., \& Muthen, B. O. (1998-2012). Mplus user's guide. Los Angeles, CA: Muthen \& Muthen.

National Academy of Engineering (2004). The engineer of 2020. Washington DC: National Academies Press.

National Research Council (2012). A framework for K-12 science education: Practices, crosscutting concepts, and core ideas. Washington DC: National Academy Press.

Nylund, K. L., Asparouhov, T., \& Muthén, B. O. (2007). Deciding on the number of classes in latent class analysis and growth mixture modeling: A Monte Carlo simulation study. Structural Equation Modeling, 14, 535-569. doi:10.1080/10705510701575396

Schmidt, A. (2011). Creativity in science: Tensions between perception and practice. Creative Education, 2, 435-445. doi:10.4236/ce.2011.25063

Trilling, B., \& Fadel, C. (2009). $21^{\text {st }}$ century skills: Learning for life in our times. San Francisco, CA: Jossey-Bass.

Yakman, G. (2010). What is STE@M? http://www.steamedu.com/ 